\title{
Grading Critical Thinking
}

\section{PHILIP A. PECORINO Queensborough Community College}

In what follows, I shall describe and defend a procedure for evaluating the performance of student's who enroll in college-level courses in critical thinking and informal logic. The particular procedure includes my own selection from among the many options available to an instructor. As settings and conditions may vary, other selections might prove more effective for realizing the same goals I aim to achieve. In many setttings the particular procedure I describe may be impractical or unworkable; nevertheless, I believe that a discussion of the goals of such courses and the evaluation procedure utilized in an effort to achieve those goals is very much in order.

To begin with I take it that the course I teach in informal logic is intended to inculcate and develop a set of intellectual skills and to promote an attitude or disposition necessary to employ those skills in life outside the classroom. If the development of skills is the objective or the primary objective of the course then the method of evaluation employed must somehow or other involve the student in the demonstration of those skills. In addition, since most students enter the course with minimal or no proficiency in these skills, the method of evaluation should not penalize the worst or reward the best for the skills they possessed upon entering the course. Further, as the skills involved in performing the tasks of argument analysis, criticism, evaluation and construction are numerous and formidable, the course should be structured in a way that addresses the skills in a piecemeal fashion, building up gradually to tasks and challenges that will require the entire range of cognitive skills and intellec- tural acts associated with critical thinking and informal logic. Evaluation should proceed piecemeal as well, with frequent occasion for feedback on the student's progress. Beyond this, the standard cautions are to be kept in mind with regard to evaluation methods, including a positive regard for the learner, the need for precise and positive criticism, etc.

In the course which I teach I have sections that range in size from twenty to forty students. Given the high rate of attrition at my institution, approximately forty percent are expected to withdraw or to disappear by the end of the semester. I have students who enter the course with competencies in reading and writing that range from sixth grade to graduate level (I usually have several New York City school teachers on sabbatical). The initial motivation for most students appears to be minimal and to center on the satisfaction of a requirement for their taking an elective course in the liberal arts and sciences. I have students read material from the textbooks before coming to class, and cover material in class using lecture and demonstration formats, calling upon them to answer questions pertaining to the material and not specific to the texts. I give out a large number of handouts and conduct a rather large number of quizzes (10) for a course lasting fourteen weeks. As I write this I am requiring my students to read Johnson and Blair's Logical Self-Defense and Vincent Barry's Invitation to Critical Thinking.

My course in informal logic is divided into nine units or sections: fallacies, advertising, information and news media, argument analysis, argument 
evaluation, argument formation, formal logic, induction and scientific reasoning, and the philosophy of logic. I cover the material in class and then administer an examination for each of the nine units. In addition I administer a final examination which is comprehensive in nature, calling upon the student to demonstrate the entire range of skills which the course has been designed to develop. The results of the final exam are compared to a similar assignment given out on the first day of class which the students are required to complete, but which is ungraded so that they need not be intimidated by an assignment so early in the course, so that I might have material with which I might make a pre/post- course comparison. Such a comparison is not only useful to the instructor in gaining a sense of the student's progress but more importantly of the instructor's effectiveness as well. In addition the comparison serves as an instrument with which the course may be evaluated, if only informally.

For each of the quizzes I give covering the nine basic units of the course I insist that the students master the skills involved to the point where they achieve a grade of eighty percent or better on each quiz. If they do not do so on their first attempt they may repeat the quiz or assignment, if you will, a number of times until they do. There are several different versions of each quiz. Each one covers the same material or set of skills but does so utilizing different text, examples and questions. Students are told that they may repeat a quiz even if they have already achieved a grade of eighty percent or better in order to raise their grade even further. I will use only the highest grade achieved for the quiz on each unit. I do not average the grades for each quiz. I do not penalize students for learning, for developing their skills or for entering without basic competencies. I allow that many students use examinations as the occasion for studying and mastering the material. Most students I have in my courses do not take too easily or responsibly to completing homework assignments. I provide many quizzes as a device to encourage their working, to give them effective response as to their progress and to demonstrate to them where they need additional development, upon their own testimony, so to speak. As long as I allow them to repeat quizzes utilizing instruments that are as challenging as the initial device so that I might provide them with appropriate critique and recommendations, and do not penalize them for attempting to demonstrate their skills again, they believe that the evaluation system is fair and do repeat the quizzes several times. As I hoped the results are encouraging. The students who repeat the quizzes do raise their grades; that is why they do it. However, what I see in the series of quizzes that a student submits is a growth process. Students do develop their skills better when asked to demonstrate them several times in a way in which they do not feel in jeopardy of embarrassing themselves or lowering their grades. With the method I have devised they can only improve their grade; they can not lower it by attempting quizzes again and again. There is a limit to the number of times a student is permitted to repeat a quiz. I set it at six times or until the grades are due, whichever comes first. This has produced the consequence of some students taking over thirty quizzes in a single semester.

The final quiz or examination is administered but once. It requires a student to perform a complete analysis and evaluation of an argument including a consideration of other relevant arguments on the same issue or topic. The students are encouraged to bring as much of what they have learned during the semester to bear in performing this examination. The final grade is determined by adding the highest scores achieved on the nine units and the final exam, each worth ten percent of the final grade. The final exam is titled such in virtue of its being the last quiz or exercise 
required of the student and because it is comprehensive in its nature. The final exam is weighted only $10 \%$ because it is not detailed nor is it more difficult or time consuming than any of the other quizzes. It is not a final exam in keeping with the common practice of having mid-term and final exam and perhaps a paper as the basis for determining the final grade. In a skill-oriented course the final quiz is the final and culminating exercise.

A word is in order as to how one instructor can possibly administer so many quizzes for so many students and still cover the material during class time and return the quiz results in a timely fashion. As I do not have teaching assistants and have precious little classroom contact time (three hours per week) I have constructed the quizzes so that students take the quizzes outside of class and may use any materials they wish to assist them. I do not permit their using other human beings to assist them in any way. The quizzes are designed to have students demonstrate skills and not to reflect what information they have memorized. Understanding of the material is a prerequisite or co-requisite for the demonstrations required in successfully completing the quizzes. As yet I have experienced no serious difficulties in accepting the results of this honorbased system of examining a student's performance.

Questions naturally arise as to how such a complicated system and so large a quantity of quizzes are actually managed. I would note once again that the sort of exercises I require of my students are, with one exception, open-ended. They are not multiple choice or short answer instruments for testing. This means that on the one hand it is easy to change the content of the exercise and yet have a quiz of the same nature and difficulty, for example the exercise that requires students to write an argument selecting from a number of topics or an exercise that requires that they cast or structure an argument taken by the instructor from the editorial pages of a local newspaper. On the other hand such quizzes are more difficult and much more time consuming to correct and evaluate. Many instructors will be put off by the number of quizzes this system for evaluation generates. When such instructors consider the nature of the quizzes themselves this system appears all the more uninviting. Although this approach is involved, I believe that despite the workload for the instructor it is very effective, more responsive to the different initial starting points of the students and, most importantly, more in keeping with the nature of the entire undertaking, i.e., the development of a set of skills. While I have had to put quite a bit more time into my teaching the course since I developed this approach I have found it quite rewarding as far as the reception it has received from the students who learn more and I believe that despite the work involved the method is fair. After several semesters of teahing this way the workload for the instructor "adjusts" due to the familiarity with the materials, likely student responses and the development of management strategies. If I taught more than two sections each having more than fifty or one hundred students and I had no teaching assistants 1 might not use this approach because I do not think that I could manage it well enough to make it work for my students, but if I could I would for more effective teaching. It is a failure of the teaching profession that there are no commonly accepted guidelines as to reasonable expectations concerning a typical "workload."

I use the multiple choice format for only one quiz, the first, which covers the "informal fallacies." I have created a computer program in the BASIC programming language which prints out such quizzes. I have entered several hundred short examples of passages containing fallacies. I took the examples from various texts and articles and I created some variations and examples of my own. I can select any number of 
them in any order for my quizzes. I usually take 25 at a time and create six quizzes each semester. It take less than five minutes total time for the selection and printing of the quiz by the personal computer. I have the printed masters duplicated by the college print shop at the start of each term. It took me as long to write the BASIC program as to enter the hundreds of items (twenty hours total). I am willing to supply the program to anyone operating an IBM compatible system who sends me a formatted diskette. Other programs are available that perform in similar fashion.

I keep statistics on the average grade received on the quizzes and so I have an idea of the relative degree of difficulty of the various versions of the multiple choice format quizzes and the individual items (my correction machine tallies the number of wrong responses for each item.) I change my quizzes on informal fallacies once a year. The quizzes on the rules of natural deduction and syllogisms are changed every other year. The argument samples used for the quizzes on casting are changed every other year as well. The quiz I give on identifying and evaluating inductive arguments I haven't changed in four years. The ninth quiz, which deals with the limits of logic, requires students to read, understand and summarize the most significant points in an article on the "Philosophy of Logic" and the essay by Charles Sanders Pierce titled, "The Fixation of Belief." I haven't changed that exercise in ten years. Having students retake this ninth quiz consists of having them rewrite their summaries of the essays in whatever time remains at the very end of the semester, which usually isn't more than a week, but it's available if they choose to exercise their option to do so or if they haven't received the minimum grade for exclusion of the repetition requirement.

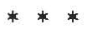

In order to provide a more concrete picture of how this approach works in practice I shall list and outline the ten exercises I actually assign. Of course the method is independent of this particular list and even this subject matter.

1. Pre-Test (ungraded) analysis and evaluation of ordinary language argument-editorial from local paper-first class;

2. Informal Fallacies: 25 questions, multiple choice;

3. Advertisements: finding examples of ten of fourteen devices in magazine, newspaper, radio or TV advertisements;

4. News Media: finding ten of over twenty-four devices and features of news presentations in print or television;

5. Casting-analysis: restatement of premises and conclusion, supplying missing premises for a supplied argument from a newspaper;

6. Construction: creating an argument, choosing topic from short list supplied;

7. Evaluation: the analysis and evaluation of the argument written by another student in exercise (quiz) 6;

8. Formal Fallacies; the analysis and evaluation of five short passages exemplifying a rule of natural deduction or a classical syllogistic pattern;

9. Induction: the analysis and evaluation of five passages illustrating inductive patterns using Mill's Methods;

10. Philosophy of Logic: the summarizing of two articles on the nature, the value and limits of logical thought;

11. Post-Test (Final Exam): a repetition of the first ungraded exercise.

***

In a course in informal logic it seems more than a bit puzzling to me how instructors could defend a system for evaluation that uses primarily objective, 
multiple choice instruments that are administered but one time and with an average of all the grades serving as the final grade. While objective exams can be constructed well enough to insure that a student has mastered material, understood concepts and applied them correctly, I do not think that the skills one would have a successful student of an informal logic course demonstrate are best evidenced through an objective testing instrument, for it will have in structure and content been leading students to certain conclusions, considerations and operations which the ordinary real-life argument presented in its natural setting will not be doing.

I have also found it difficult to accept the notion that students must demonstrate whatever it is they are expected to give evidence of on a single occasion. While there are times when life presents us with but one opportunity to prove something or to choose or decide, that does not in itself commend such a one-shot arrangement as the most effective for achieving our pedagogic goals. Beyond this I see no acceptable argument for penalizing students who enter a course without the knowledge or skills that a course intends to transmit for their not having such knowledge or skills in the first place-which is what averaging the scores of a first test, done poorly, with a subsequent test involving the same material, done well, does to the student.

The process of evaluation which I have described is one which emphasizes the development of skills, the encouragement of the student's work at the development of such skills and the demonstration of such skills in ways that are truer to real life situations. I hope that this brief description and defense of a method for evaluating the achievements of a student in an informal logic class will open up the discussion of such issues among my colleagues.

Professor Philip A. Pecorino, Queensborough Community College, Bayside, New York, 11364 